\title{
Students' Perception of Digital Library as a Media for Supporting Student Centred Active Learning
}

\author{
Arfah Habib Saragih \\ arfah.habib11@ui.ac.id \\ Faculty of Administrative Science, Universitas Indonesia
}

\begin{abstract}
The use of Digital Library (Digilib) has grown rapidly. As a library management information system that can assist users to search for references, it cannot be denied that the establishment of Digilib has assisted numerous students. In order for information technology to improve organizational performance, the technology must be accepted and utilized by its users. This quantitative research aims to identify students' perceptions of digital library at the Central Library, Universitas Indonesia. A questionnaire is distributed to 109 respondents. The data analysis employs structural equation model toward the Unified Theory of Acceptance and Use of Technology (UTAUT) model. The results of the analysis show that performance expectation significantly affects the behaviour intention of digital library users. On the other hand, effort expectation, social influence, and facilitating condition do not influence behaviour intention. Meanwhile, behaviour intention has a significant effect on use behaviour. The implication of this findings is that the Central Library of Universitas Indonesia should improve the digital library so that it can support the student centred active learning at the university.
\end{abstract}

Keywords: UTAUT Model, Digital Library, Student Centred Active Learning

\section{Introduction}

The University of Indonesia (UI) has a vision to become a superior and competitive center of science, technology, and culture through efforts in educating the community to increase public welfare, so it may contribute to the development of the people of Indonesia and the world. In order to accomplish this vision, the University of Indonesia is always improving its capacity and capability in developing science and technology with a variety of missions such as providing wide and fair access, as well as quality education and teaching; conducting quality Tridharma activities which are relevant to the challenges of the nation and the world; producing graduates who are highly intellectual, virtuous, and able to compete globally; as well as creating an academic environment that is able to support the accomplishment of the vision of the University of Indonesia.

Much has been done in advancing UI to accomplish its vision. One of these efforts is the establishment of the UI Digital Library (UI Digilib). The Digilib is a library management information system that can assist users to search for books, articles, magazines, undergraduate and postgraduate theses and dissertations, as well as a variety of other reading sources in the library. This system makes it easy for users to find the references they are looking for. The creation of the UI Digilib is expected to further support the vision of UI because it will open larger opportunities for academics to obtain a variety of reference 
materials required for academic needs, research, etc. In the digital library literature, the term "digital library" has come to denote an electronic library, online library, library without walls, hybrid library, desktop library, and virtual library [1].

The UI Digilib also makes it possible for UI academics, be it students or lecturers, to gain easier access to information online that can be done anytime and anywhere to support their academic progress. The UI Digilib provides plentiful information and materials such as collections of compulsory as well as supporting books; UI undergraduate and postgraduate theses and dissertations; new collections; numerous articles, magazines, journals, bulletins, research reports, and CDROMs; e-articles and e-books; links to download materials; online databases; etc. It cannot be denied that the establishment of the UI Digilib has assisted numerous people (such as students, lecturers and library staff) in terms of convenience, effectivity, efficiency in many aspects concerning the materials/references needed for assignments, theses, dissertations and other forms of research for UI students and lecturers.

As the largest group of users of the UI Digilib, students highly require important and vast information regarding the references they need. Considering the importance of UI Digilib as a system that provides a variety of information on reference materials, the author was interested in conducting research in this area. In order for information technology to improve organizational performance, the technology must be accepted and utilized by its users; in this case the users are the students and lecturers. The level of acceptance of the information system by its users can serve as a benchmark to measure the acceptance of a certain information technology by its users. One of the methods that can be used to measure the acceptance and usage of technology is the Unified Theory of Acceptance and Use of Technology (UTAUT) [2].

UTAUT is a model that explains user behavior towards information technology [2]. This model is a combination of eight models that were previously developed. The UTAUT model shows that the intention for behavior (behavioral intention, BI) and the behavior to use a particular technology (use behavior, UB) is affected by performance expectancy, effort expectancy, social influence, and facilitating conditions. These four factors are moderated by factors of gender, age, experience and voluntariness of use.

Performance expectancy (PE) describes how much a person believes that using a particular system will help gain performance advantages in his/her work; Effort expectancy (EE) is defined as the level of ease associated with the use of a system, if a system is easy to use, then not much effort will be exerted, and vice versa; Social influence (SI) describes how far an individual perceives the importance of something trusted by other people will influence him/her in using a new system; and Facilitation conditions (FC) is defined as how much a person believes that the organizational and technical infrastructure is available to support the system.

Empirical studies that have adopted this model have been conducted numerous times, and have resulted in diverse findings. Based on previous studies that have also investigated the user acceptance of digital libraries, it was found that PE, EE, and SI has a significant effect on BI [3][4][5], whereas FC also had an effect on UB [3], and BI had a significant effect on UB[3][4][5]. Meanwhile, other study results found that PE, EE, SI did not have an effect on BI [6]. Other findings showed that PE, SI, FC, hedonic motivation, habit, and information quality has a significant association with BI to adopt a digital library except for effort expectancy [7].

The previous studies have also proved that almost all students satisfied with current digital library features and functionality, they recommended the addition of more documents related to their courses and useful links to the digital library [8]. Users also satisfied with the 
authenticity of information in available databases [1]. In addition, perceived usefulness and digital library's affinity has significant effect on user satisfaction and user loyalty [9]. On the other hand, the previous surveys have also found that some users often do not know how to optimalize the use the digital library because they are unaware of all of the services offered [10]. In order to solve this problem, one of the solution is by offering more services more staff assistance [10].

This study is deemed important because it will assist in understanding the perceptions of students on the acceptance of the UI Digilib and identify the factors that may affect the intention of the users/students in using UI Digilib through the application of the UTAUT Model. The research questions in this study are the effects of Performance Expectancy, Effort Expectancy, Social Influence on Behavioral Intention and the effect of Facilitating Condition and Behavioral Intention on Actual Use Behavior. It is expected that this research may contribute in discovering user acceptance of the UI Digilib and the factors that affect user intention in its usage. This will be useful in the future development of the UI Digilib so that it may be more widely accepted by its users by considering which factors of the Digilib affect user intention, and which need further development.

\section{Method}

The research data is primary data obtained through the distribution of questionnaires to students as respondents. Data sample collection is carried out randomly with a total sample of 109 respondents. The data processing technique used in this research comprised of the Structural Equation Model (SEM) in the form of Partial Least Square assisted by the SmartPLS software. SEM is an analysis method that is very widely used to describe the model that includes relationships between several variables. One of the advantages of SEM is its ability to directly analyze relationship patterns between latent variables and indicators, latents and latents, and calculate the measurement error rate that occurs. The confidence level used in this study is $95 \%$. Additionally, the steps in performing PLS are: evaluating the measurement model (outer model), Convergent Validity, Discriminant Validity, Composite Reability; evaluating the structural model (inner model), R-Square Test, Q-Square Test; designing the flow diagram and Full Structural Model diagram; and creating a model equation system (equation table and model).

In order to answer the research questions, five hypotheses were formulated:

H1: Performance Expectancy (PE) has an effect on Behavioral Intention (BI)

H2: Effort Expectancy (EE) has an effect on Behavior Intention (BI)

H3: Social Influence (SI) has an effect on Behavior Intention (BI)

H4: Facilitating Condition (FC) has an effect on Use Behavior (UB)

H5: Behavioral Intention (BI) has an effect on Use Behavior (UB)

\section{Result and Discussion}

Results were obtained based on data processing results from the SmartPLS software, which can be seen on Figure 1 and Table 1. A Model Equation of this study can be formulated from Figure 1: Use Behavior = Behavioral Intention*0.752 + Performance Expectation*0.680 + Effort Expectation*0.057 + Social Influence* $0.139+$ Facilitating Condition*0.039 + Error. 
Additionally the value of Adjusted R Square model for the effect of PE, EE, SI on BI was $62.10 \%$, while for the model of the effect of FC, BI on UB was $59.70 \%$. This indicates that BI in the use of the digital library can be explained as $62.10 \%$ by PE, EE, and SI. Meanwhile UB in the use of the digital library can be explained as $59.70 \%$ by FC and BI. The data processing results of the effects of independent variables on dependent variables can be viewed on Table 1. From the five hypotheses developed, $\mathrm{H} 1$ and $\mathrm{H} 5$ were proven, while $\mathrm{H} 2, \mathrm{H} 3$, and $\mathrm{H} 4$ were disproven.

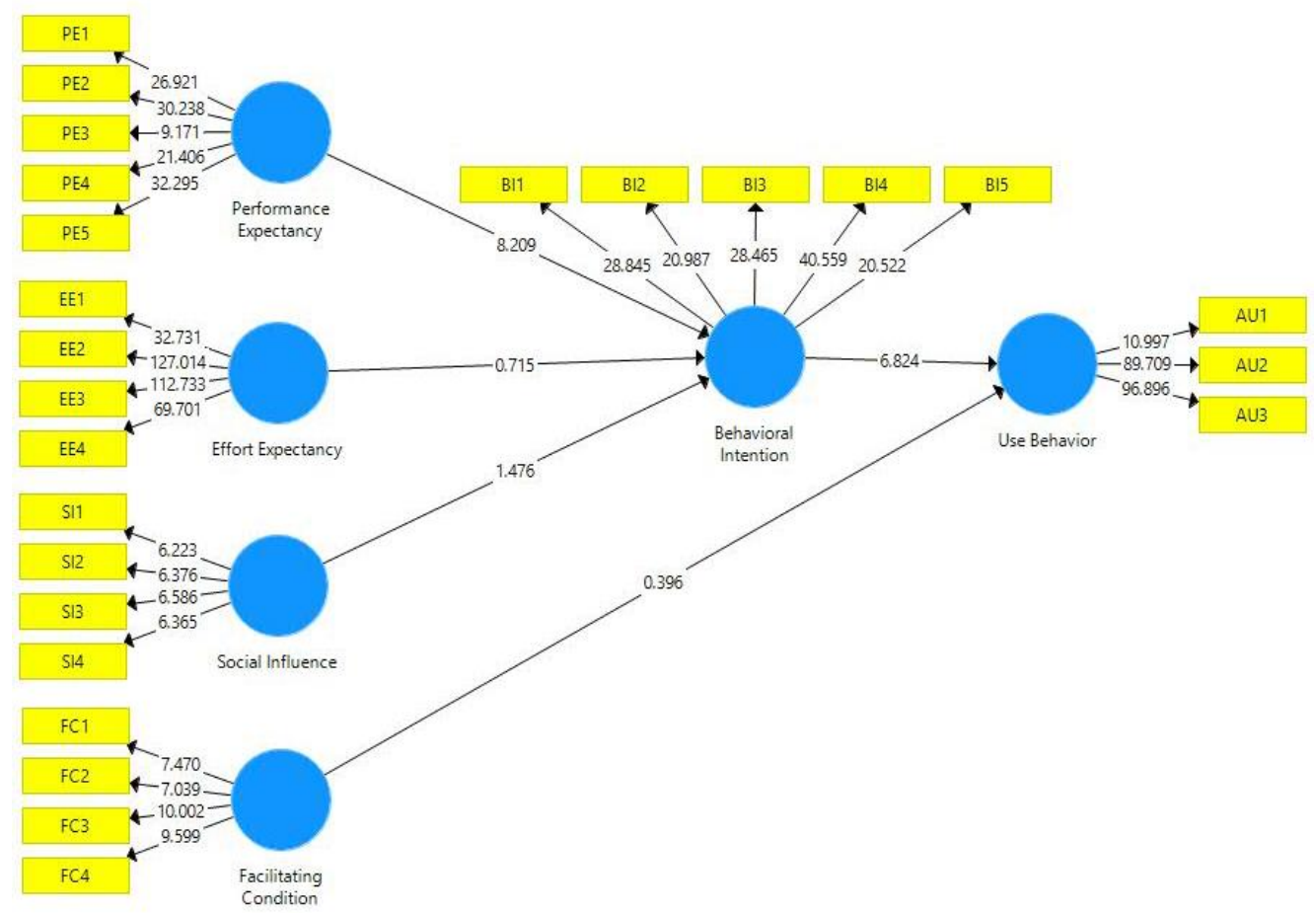

Fig. 1. Structural model results

Table 1. Direct and indirect effects of independent variables

\begin{tabular}{cccccccc}
\hline $\begin{array}{c}\text { Independent } \\
\text { Variable }\end{array}$ & $\begin{array}{c}\text { Dependent } \\
\text { Variable }\end{array}$ & Hypothesis & Path & $\begin{array}{c}\text { Original } \\
\text { Sample }\end{array}$ & t-Statistic & t-Table & Result \\
\hline PE & BI & PE $\rightarrow$ BI & H1 & 0.680 & 8.209 & 1.96 & Supported \\
EE & BI & EE $\rightarrow$ BI & H2 & 0.057 & 0.715 & 1.96 & Rejected \\
SI & BI & SI $\rightarrow$ BI & H3 & 0.139 & 1.476 & 1.96 & Rejected \\
FC & UB & FC $\rightarrow$ UB & H4 & 0.039 & 0.396 & 1.96 & Rejected \\
BI & UB & BI $\rightarrow$ UB & H5 & 0.752 & 6.824 & 1.96 & Supported \\
\hline
\end{tabular}

The effect of performance expectancy on behavioral intention (H1). Based on data processing results, $\mathrm{PE}$ was proven to have a positive effect on $\mathrm{BI}$, hence $\mathrm{H} 1$ was proven. This was because the students felt that the digital library was beneficial to their studies, was good support for completing their assignments faster because adequate reference sources were available, the resulting assignments were of good quality because the reference sources were 
guaranteed, and could increase productivity in the search of reference sources; this led to the increase of behavior intention in using the digital library.

The effect of effort expectancy on behavioral intention (H2). EE was found to not have a significant effect on $\mathrm{BI}$, hence $\mathrm{H} 2$ was rejected. This was possibly due to the students lacking the skills in operating the digital library so that it resulted them feeling that it was difficult to use. This may give input to the university library to provide regular socialization and training to students to optimalize the usage of the digital library, as well as providing electronic guide books as well as tutorial videos on the use of the digital library that can be downloaded on the university library website.

The effect of social influence on behavioral intention (H3). Table 3 also shows that SI did not have an effect on BI, hence $\mathrm{H} 3$ was also rejected. This indicated that the social environment of the students on campus was not very supportive for a wider and more intensive use of the digital library. Based on the answers on the questionnaires, the average of respondents felt that their friends, seniors, assistant lecturers and lecturers did not much promote the digital library as a quality reference source in searching for the references needed for their assignments. This may serve as input for all civitas academia, especially lecturers and assistant lecturers to better promote the use of the digital library as a media to find good quality reference sources.

The effect of facilitating condition on use behavior (H4). The next unsupported hypothesis was $\mathrm{H} 4$, facilitating condition was also found to not have a significant effect on use behavior in the use of the digital library. On average the respondents felt that the stability of the internet on campus affected their access to the digital library. Moreover, there was not enough dedicated library staff to assist them if they had difficulties in using the digital library. This information can serve as input for the university to minimalize internet network errors on campus as well as providing dedicated staff to assist the students whenever they face difficulties in operating the digital library when searching for reference sources. Additionally, the updating of the reference collection, especially undergraduate and postgraduate theses and dissertations, is also very required in supporting the facilitating condition of the use of the digital library.

The effect of behavioral intention on use behavior (H5). The final results show that BI had a significant positive effect on UB, hence H5 is proven. This is a good signal because the intention of the students in the use of the digital library as a media for the searching of reference sources has a positive effect on its actual usage and will recommend this media as a supporting element in completing a variety of university assignments.

\section{Conclusion}

The implications of these findings are: the university should make improvements in several areas such as conducting performing regular socialization and training to students to optimalize the use of the digital library, and also providing electronic guide books and tutorial videos on its use that can be downloaded on the university library website. Moreover, it is also important to minimalize internet network errors on campus, because this will hinder the use of this media which needs to be connected to the internet to access all the references subscribed by UI. Dedicated staff to assist the students whenever they face difficulties in using the digital library is also needed. Additionally, lecturers and assistant lecturers can also become key actors to better promote the use of the digital library as a media to search for good quality 
research sources. Based on the research results of this study, it was found that H1 and H5 were proven, while $\mathrm{H} 2, \mathrm{H} 3$, and $\mathrm{H} 4$ were disproven. Performance Expectancy had a significant effect on Behavioral Intention in the use of the digital library; Effort Expectancy and Social Influence had no effect on Behavioral Intention; Facilitating Condition had no effect on Use Behavior; and Behavioral Intention has a significant effect on Use Behavior. Lastly, the library also needs to regularly update its reference collection, especially the most recent undergraduate and postgraduate theses and dissertations that is highly required to support the facilitation condition of digital library usage.

\section{Acknowledgments}

The author is grateful to the University of Indonesia because this research is undertaken at the University of Indonesia.

\section{References}

[1] M. Jabeen, Y. Qinjian, Z. Yihan, M. Jabeen, and M. Imran, "Usability study of digital libraries: An analysis of user perception, satisfaction, challenges, and opportunities at university libraries of Nanjing, China," Libr. Collect. Acquis. Tech. Serv., vol. 40, no. 1-2, pp. 58-69, 2017.

[2] J. Nozières and M. Ghidini, "Thermal excitations in quasi-one-dimensional amorphous ferromagnetic wires," Phys. Rev. B - Condens. Matter Mater. Phys., vol. 57, no. 22, pp. R14040-R14043, 1998.

[3] M. S. Awwad and S. M. Al-Majali, "Electronic library services acceptance and use An empirical validation of unified theory of acceptance and use of technology," Electron. Libr., vol. 33, no. 6, pp. 1100-1120, 2015.

[4] M. Arif, K. Ameen, and M. Rafiq, "Factors affecting student use of Web-based services: Application of UTAUT in the Pakistani context," Electron. Libr., vol. 36, no. 3, pp. 518-534, 2018.

[5] S. S. Chang, S. J. Lou, S. R. Cheng, and C. L. Lin, "Exploration of usage behavioral model construction for university library electronic resources," Electron. Libr., vol. 33, no. 2, pp. 292-307, 2015.

[6] F. W. Singeh, A. Abrizah, and N. H. A. Karim, "Malaysian authors' acceptance to self-archive in institutional repositories: Towards a unified view," Electron. Libr., vol. 31, no. 2, pp. 188-207, 2013.

[7] K. Moorthy, L. Chun T'ing, K. S. Ming, C. C. Ping, L. Y. Ping, L. Q. Joe, and W. Y. Jie, "Behavioral Intention to Adopt Digital Library by the Undergraduates," Int. Inf. Libr. Rev., vol. 0, no. 0, pp. 1-17, 2018.

[8] N. K. Sheeja, "Undergraduate students' perceptions of digital library: A case study," Int. Inf. Libr. Rev., vol. 42, no. 3, pp. 149-153, 2010.

[9] F. Xu and J. T. Du, "Factors influencing users' satisfaction and loyalty to digital libraries in Chinese universities," Comput. Human Behav., vol. 83, pp. 64-72, 2018.

[10] A. M. Tammaro, "User perceptions of digital libraries: A case study in Italy," Perform. Meas. Metrics, vol. 9, no. 2, pp. 130-137, 2008. 
